\title{
'COMPARISON BETWEEN LINEZOLID VERSUS VANCOMYCIN IN TREATMENT OF DIABETIC PATIENTS WITH NOSOCOMIAL PNEUMONIA CAUSED BY METHICILLIN RESISTANT STAPH AUREUS
}

By

\section{Islam Nomeir Mohamed El-Morsy, Abu Bakr Helal El-Asmar and Abdallah Soliman Ayoob}

Department of Chest diseases Faculty of medicine, Al-Azhar University

Corresponding author: Islam Nomeir Mohamed El-Morsy,

Mobile: 01009348000; E-mail: islam.nomeir@ outlook.com

\begin{abstract}
Background: The optimal antibiotic therapy for the treatment of hospital acquired pneumonia (HAP) caused by Methicillin-resistant Staphylococcus aureus (MARSA) is controversial especially in diabetes mellitus patients. However, certain researches recommended that linezolid is superior to vancomycin in management of HAP.

Objective: To assess the effect of treatment outcomes in patients with nosocomial pneumonia caused by methicillin- resistant staph aureus in diabetic patients and non-diabetic patients.

Patients and Methods: This study was conducted on 120 patients at Mansoura Chest Diseases Hospital, Mansoura, Egypt, in the period between December 2019 and August 2020 among patients whose age more than 18 years old. Group A ( $n=60)$ : Diabetic cases which further subdivided into two subgroups: Group A1 $(n=30)$ : Diabetic patients with nosocomial pneumonia receiving linezolid. Group A2 $(n=30)$ : Diabetic patients with nosocomial pneumonia receiving vancomycin. Group B $(n=60)$ : Non- diabetic cases, which further subdivided into two subgroups: Group B1 $(n=30)$ : Non-diabetic patients with nosocomial pneumonia receiving linezolid. Group B2 $(\mathrm{n}=30)$ : Non-diabetic patients with nosocomial pneumonia receiving vancomycin.
\end{abstract}

Results: APACHE score and duration of hospital admission were higher in diabetic cases in comparison with non-diabetic cases with statistically significant differences. Diabetic cases were more liable for complications with a subsequent high mortality rates in comparison with non-diabetic ones irrespective of the current usage of antibiotics (weather linezolid or vancomycin). Treatment outcomes were comparable among Linezolid and vancomycin used groups. The need for mechanical ventilation was comparable among all groups with no statistically significant difference.

Conclusion: Diabetic comorbidity remains the main factor that affects the outcomes and prognosis of HAP cases. Higher complications and mortality rates were more in diabetic cases owing to their renal condition and uncontrolled diabetic status. Linezolid and vancomycin have similar efficacy and safety profiles in management of HAP cases.

Keywords: HAP, Vancomycin, Linezolid, nosocomial pneumonia, Diabetic cases, APACHE score. 


\section{INTRODUCTION}

Persons with diabetes mellitus, compared with non- diabetic persons, have higher rates of impaired immunity, decreased lung function, and an increased risk for various types of infection, including pneumonia (Meyer et al., 2010).

Patients with diabetes appear to be at increased risk for acquiring $S$. aureus pneumonia, and patients requiring renal dialysis are at risk for hospital-acquired pneumonia, healthcare associated pneumonia and ventilator associated pneumonia caused by multi-drug resistant pathogens (Djahmi et al., 2013).

Current guidelines for the management of adults with hospital-acquired, ventilator-associated and healthcareassociated pneumonia issued jointly by the American Thoracic Society and the Infectious Diseases Society of America (IDSA) recommend either linezolid or vancomycin as appropriate antibiotic agents for the treatment of MRSA nosocomial pneumonia (NP) (Kalil et al., 2016).

This metabolic disorder causes damage in multiple organs. Moreover, several aspects of immunity are altered in patients with diabetes. The normal role of polymorphonuclear leukocytes, leukocyte adherence, chemotaxis, and the processes of phagocytosis may all be compromised. Antioxidant systems involved in bactericidal activity can also be impaired (Di Yacovo et al., 2013).

However, the impact that these disturbances have on the development and outcomes of infectious diseases has been poorly studied.
The present study was conducted to assess the effect of treatment outcomes in patients with nosocomial pneumonia caused by methicillin-resistant staph aureus in diabetic patients and nondiabetic patients.

\section{PATIENTS AND METHODS}

This study was conducted on 120 patients whose age more than 18 years old at Mansoura chest diseases hospital, Mansoura, Egypt. in the period between December 2019 till August 2020. A total of 120 patients were divided into two groups (group A and group B). Each group was subdivided into two subgroups as follows: Group A $(\mathbf{n = 6 0})$ : Diabetic cases which further subdivided into two subgroups: Group A1 $(\mathbf{n = 3 0})$ : Diabetic patients with nosocomial pneumonia receiving linezolid. Group A2 $(\mathbf{n}=\mathbf{3 0})$ : Diabetic patients with nosocomial pneumonia receiving vancomycin. Group B $(\mathbf{n}=60)$ : Non- diabetic cases, which further subdivided into two subgroups: Group B1 $(\mathbf{n = 3 0})$ : Non-diabetic patients with nosocomial pneumonia receiving linezolid. Group B2 $(\mathbf{n = 3 0})$ : Non-diabetic patients with nosocomial pneumonia receiving vancomycin.

\section{Inclusion Criteria:}

All patients with nosocomial pneumonia more than 18 years old.

\section{Exclusion Criteria:}

Patients with tuberculosis, with autoimmune diseases, with malignant diseases, receiving corticosteroids, with collagen disorders, receiving cytotoxic drugs, refuse the participation in the study and less than 18 years old. 


\section{All patients were subjected to the following:}

Full clinical history, full clinical examination, radiological investigations (Plain Chest X-ray and CT chest) and laboratory investigations (Complete blood count (CBC), liver function tests (LFT): ALT and AST, Kidney function tests (KFT): serum creatinine, arterial blood gases (ABG), culture and sensitivity, continuous assessment of blood glucose level: fasting blood glucose, postprandial blood glucose and $\mathrm{HbA1c}$.

Ethical consideration: An informed consent was taken from every patient before enrollment in the study after approval of the Institutional Research Board (IRB) of Faculty of Medicine at Mansoura University.

\section{Statistical analysis:}

IBM's SPSS statistics (Statistical Package for the Social Sciences) for windows (version 25, 2017) was used for statistical analysis of the collected data. Shapiro-Wilk test was used to check the normality of the data distribution. All tests were conducted with $95 \%$ confidence interval. $\mathrm{P}$ (probability) value $<0.05$ was considered statistically significant.

Descriptive: Quantitative variables were expressed as mean and standard deviation while categorical variables were expressed as frequency and percentage.

\section{Continuous Group differences:} Independent sample $\mathrm{T}$ test was used to compare 2 means. One-way ANOVA with Bonferroni post hoc analysis was used for inter-group (between subjects in three or more groups) comparison.

Categorical Group differences: Fisher exact and Chi square tests were used for inter-group comparison of nominal data using the crosstabs function.

\section{RESULTS}

Table (1) showed the demographic characteristics and medical history of 2 groups a Diabetes mellitus (DM) group and a Non-DM group and each group had 100 patients, the average age of DM group was 62.73 years \pm Standard deviation (SD) 7.576 and the average age of the Non Dm group was 61.60 years \pm (SD) 7.226 , this difference did not show any statistically significance among the results of this study $(\mathrm{P}>0.05)$.

The average weight of DM group was $93.10 \mathrm{~kg} \pm 17.768$ and the average weight of Non-DM group was $95.56 \mathrm{~kg} \pm 19.313$, this difference did not show any statistically significance among the results of this study $(\mathrm{P}>0.05)$.
DM group had 56 males (56\%) and 44 females (44\%), while Non-DM group had 52 males $(52 \%)$ and 48 females (48\%), this difference did not show any statistically significance among the results of this study $(\mathrm{P}>0.05)$.

There were 62 patients $(62 \%)$ had hypertension (HTN) in DM group, while Non-DM group had 52 patients (52\%) with HTN, this difference did not show any statistically significance among the results of this study $(\mathrm{P}>0.05)$.

DM-group had 13 patients (13\%) with liver diseases while Non-DM group had 11 patients $(11 \%)$ with Liver diseases, this difference did not show any statistically 
significance among the results of this study $(\mathrm{P}>0.05)$.

DM group had 53 patients (53\%) with renal diseases while Non-DM group had 22 patients $(22 \%)$ with renal diseases, this difference showed statistically significance among the results of this study $(\mathrm{P}<0.005)$. So, the presence of DM had an effect on the kidneys in this study.
The average random blood sugar (RBS) in DM group was $147.56 \mathrm{mg} / \mathrm{dl} \pm$ SD 20.873 while the average RBS in Non-DM group was $105.04 \mathrm{mg} / \mathrm{dl} \pm 21.795$, this difference showed statistically significance among the results of this study $(\mathrm{P}<0.005)$. So, the presence of DM had an effect on the results of RBS of this study.

Table (1): Demographic characteristics and medical history of DM and NON-DM groups

\begin{tabular}{|c|c|c|c|c|c|}
\hline \multicolumn{2}{|c|}{$\begin{array}{l}\text { Groups } \\
\text { Parameters }\end{array}$} & $\begin{array}{c}\text { DM group } \\
(n=100)\end{array}$ & $\begin{array}{c}\text { Non-DM group } \\
(\mathbf{n}=\mathbf{1 0 0})\end{array}$ & $95 \% \mathrm{CI}$ & $\mathbf{p}$ \\
\hline \multicolumn{2}{|c|}{ Age } & $62.73 \pm 7.576$ & $61.60 \pm 7.226$ & $-0.93,3.19$ & 0.282 \\
\hline \multicolumn{2}{|c|}{ Weight } & $93.10 \pm 17.768$ & $95.56 \pm 19.313$ & $-7.64,2.71$ & 0.348 \\
\hline \multirow{2}{*}{$\begin{array}{c}\text { Gender } \\
\text { Gender } \\
\text { HTN }\end{array}$} & Male & $56.0 \%(56)$ & $52.0 \%(52)$ & \multirow[b]{2}{*}{$-0.18,0.1$} & \multirow[b]{2}{*}{0.570} \\
\hline & Female & $44.0 \%(44)$ & $48.0 \%(48)$ & & \\
\hline \multicolumn{2}{|c|}{ Hepatic } & $62.0 \%(62)$ & $52.0 \%(52)$ & $-0.24,0.04$ & 0.153 \\
\hline \multicolumn{2}{|c|}{ Hepatic } & $13.0 \%(13)$ & $11.0 \%(11)$ & $-0.11,0.07$ & 0.663 \\
\hline \multicolumn{2}{|c|}{ Renal } & $53.0 \%(53)$ & $22.0 \%(22)$ & $-0.44,-0.18$ & $<0.001$ \\
\hline \multicolumn{2}{|c|}{ RBS } & $147.56 \pm 20.873$ & $105.04 \pm 21.795$ & $36.57,48.47$ & $<0.001$ \\
\hline
\end{tabular}

Table (2) showed laboratory investigations and radiological workups done to the both groups, and there was Infiltration in X-ray in 27 patients $(27 \%)$ unilaterally and in 73 patients $(73 \%)$ bilaterally in DM group, while Infiltration in X-ray was unilateral in 26 patients $(26 \%)$ and bilateral in 74 patients $(74 \%)$ in Non-DM group, this difference in infiltration in X-ray of the both groups did not show any statistically significance on the results of this study $(\mathrm{P}>0.05)$.

Pleural effusion was found in 52 patients $(52 \%)$ in DM group and in 44 patients (44\%) in Non-DM group, and this difference in finding Pleural effusion in both groups did not show any statistically significance on the results of this study $(\mathrm{P}>0.05)$.

Bacteremia was found in 10 patients $(10 \%)$ in DM group and in 9 patients $(9 \%)$ in Non-DM group, and this difference in finding Bacteremia in both groups did not show any statistically significance on the results of this study $(\mathrm{P}>0.05)$.

The organisms found in DM group were MRSA in 64 patients (64\%), $\mathrm{G}$-ve in 18 patients $(18 \%)$ and $G$ +ve in 18 patients $(18 \%)$ while in Non-DM group there were MRSA in 56 patients $(56 \%), \mathrm{G}$ -ve in 30 patients $(30 \%)$ and $\mathrm{G}+\mathrm{ve}$ in 14 patients $(14 \%)$, and this difference of the type of the organisms in the both groups did not show any statistically significance on the results of this study $(\mathrm{P}>0.05)$. 
Table (2): Laboratory investigations and radiological workup of DM and Non-DM groups

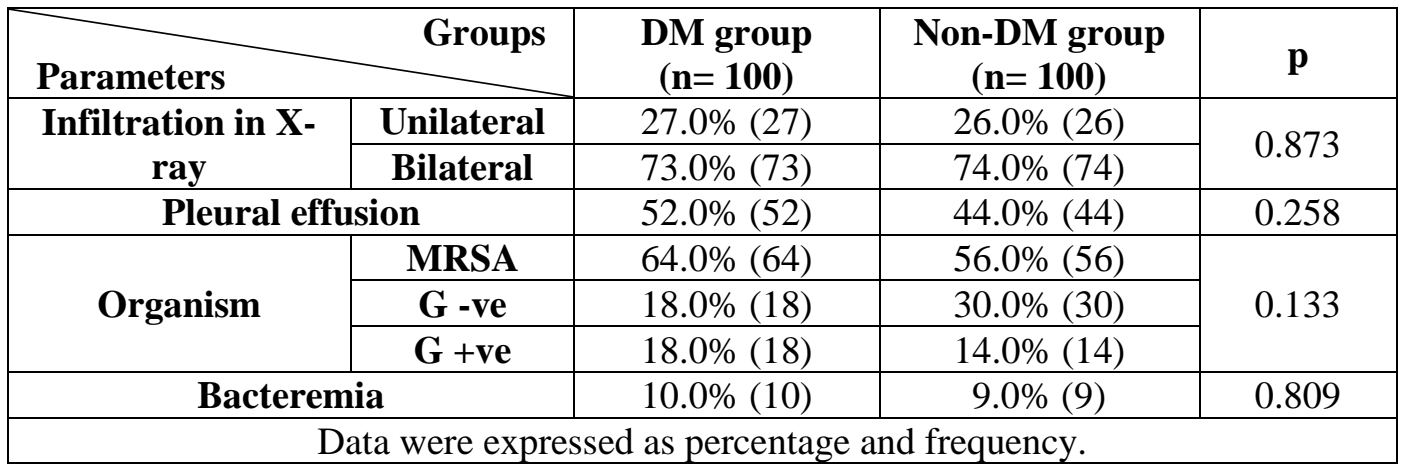

Table (3) showed the need for insulin and mechanical ventilation in the both groups. There were 72 cases $(72 \%)$ who needed insulin in DM group and no cases needed insulin in Non-Dm group and this difference showed statistically significance between the both groups $(\mathrm{P}<0.005)$. So, the need of Insulin had effect on the results of this study. 47 patients $(47 \%)$ needed Mechanical ventilation in DM group, while 45 cases $(45 \%)$ in Non-DM group needed Mechanical ventilation. This difference did not show any statistically significance on the results of this study ( $>>0.05)$.

Table (3): Need for insulin and mechanical ventilation in DM and NON- DM groups

\begin{tabular}{|c|c|c|c|}
\hline Groups & $\begin{array}{c}\text { DM group } \\
(\mathbf{n = 1 0 0})\end{array}$ & $\begin{array}{c}\text { Non-DM group } \\
(\mathbf{n = 1 0 0})\end{array}$ & $\mathbf{p}$ \\
\hline Parameters & $72.0 \%(72)$ & $0.0 \%(0)$ & $<\mathbf{0 . 0 0 1}$ \\
\hline $\begin{array}{c}\text { Mechaulin } \\
\text { ventilation }\end{array}$ & $47.0 \%(47)$ & $45.0 \%(0)$ & 0.777 \\
\hline \multicolumn{2}{|r|}{ Data were expressed as percentage and frequency. } \\
\hline
\end{tabular}

Table (4) showed APACHE score and duration of hospital admission in the both groups. The average APACHE score in DM group was $19.13 \pm$ SD 2.870 and in Non-DM group was $16.95 \pm$ SD 2.794 . This difference showed statistically significance in the results of this study $(\mathrm{P}<0.005)$, so the APACHE score had effect on the results of this study. The average duration of hospital admission in DM group was $12.52 \pm$ SD 2.859 and in Non-DM group was $11.61 \pm$ SD 2.628. This difference showed statistically significance in the results of this study $(\mathrm{P}<0.05)$, so the duration of hospital admission had effect on the results of this study. 
Table (4): APACHE score and duration of hospital admission in DM and NON-DM groups

\begin{tabular}{|c|c|c|c|c|}
\hline Groups & $\begin{array}{c}\text { DM group } \\
(\mathbf{n = 1 0 0})\end{array}$ & $\begin{array}{c}\text { Non-DM group } \\
(\mathbf{n = 1 0 0})\end{array}$ & $\mathbf{9 5 \%} \mathbf{C I}$ & $\mathbf{p}$ \\
\hline Parameters & $19.13 \pm 2.870$ & $16.95 \pm 2.794$ & $1.39,2.97$ & $<\mathbf{0 . 0 0 1}$ \\
\hline APACHE & $12.52 \pm 2.859$ & $11.61 \pm 2.628$ & $0.14,1.68$ & $\mathbf{0 . 0 2 0}$ \\
\hline Duration & \multicolumn{4}{|c|}{} \\
\hline \multicolumn{2}{|c|}{ Data were expressed as mean and standard deviation. 95\% CI: 95\% confidence } \\
interval of the mean difference between both groups.
\end{tabular}

Table (5) showed the treatment outcomes in DM versus Non-DM groups. The prevalence of poor (Complications) outcomes were $41.0 \%(41)$ and $26.0 \%$ (26) while the prevalence of good outcomes was $59.0 \%(59)$ and $74.0 \%(74)$ in DM group and Non-DM group respectively with highly statistically significant difference $(\mathrm{P}<0.05)$.

Table (5): Treatment outcome in DM and Non-DM groups

\begin{tabular}{|c|c|c|c|}
\hline Treatment outcome & $\begin{array}{c}\text { DM group } \\
(\mathbf{n = 1 0 0})\end{array}$ & $\begin{array}{c}\text { Non-DM group } \\
(\mathbf{n = 1 0 0})\end{array}$ & p \\
\cline { 1 - 3 } Poor (Complications) & $41.0 \%(41)$ & $26.0 \%(26)$ & \multirow{2}{*}{$\mathbf{0 . 0 2 5}$} \\
\cline { 1 - 3 } & $59.0 \%(59)$ & $74.0 \%(74)$ & \\
\hline \multicolumn{2}{|r|}{ Good } & \multicolumn{2}{|c|}{ Data were expressed as percentage and frequency. }
\end{tabular}

Table (6) showed Demographic characteristics and medical history of 2 groups which are Linezolid and Vancomycin groups, the average age of Linezolid group was 63.27 years \pm SD 6.980 and the average age of the Vancomycin group was 61.06 years \pm SD 7.686, this difference showed statistically significance among the results of this study $(\mathrm{P}<0.05)$. So, the age had effect on the results when comparing those both groups.

The average weight of Linezolid group was $94.99 \mathrm{KG} \pm \mathrm{SD} 17.536$ and the average weight of Vancomycin group was $93.67 \mathrm{~kg} \pm \mathrm{SD} 19.580$, this difference showed statistically significance among the results of this study $(\mathrm{P}<0.05)$. Therefore, the weight had effect on the results when comparing those both groups.

Linezolid group had 48 males $(48 \%)$ and 52 females (52\%), while Vancomycin group had 60 males $(60 \%)$ and 40 females $(40 \%)$, this difference did not show any statistically significance among the results of this study $(\mathrm{P}>0.05)$.
There were 63 patients $(63 \%)$ had hypertension (HTN) in Linezolid group, while Vancomycin group had 51 patients $(51 \%)$ with HTN, this difference did not show any statistically significance among the results of this study $(\mathrm{P}>0.05)$.

Linezolid group had 11 patients $(11 \%)$ with liver diseases while Vancomycin group had 13 patients (13\%) with Liver diseases, this difference did not show any statistically significance among the results of this study $(\mathrm{P}>0.05)$.

Linezolid group had 30 patients $(30 \%)$ with renal diseases while Vancomycin group had 45 patients (45\%) with renal diseases, this difference showed statistically significance among the results of this study $(\mathrm{P}<0.05)$. So, the drugs had an effect on the results of this study.

The average random blood sugar (RBS) in Linezolid group was $123.6 \mathrm{mg} / \mathrm{dl} \pm \mathrm{SD} 23.259$ while the average RBS in Vancomycin group was $129 \mathrm{mg} / \mathrm{dl} \pm \mathrm{SD} 35.61$, this difference did not show any statistically significance among the results of this study ( $>>0.05)$. 
Table (6): Demographic characteristics and medical history of Linezolid and Vancomycin groups

\begin{tabular}{|c|c|c|c|c|c|}
\hline \multicolumn{2}{|c|}{$\begin{array}{l}\text { Groups } \\
\text { Parameters }\end{array}$} & $\begin{array}{c}\text { Linezolid group } \\
(\mathrm{n}=\mathbf{1 0 0})\end{array}$ & $\begin{array}{c}\text { Vancomycin group } \\
(n=100)\end{array}$ & $95 \% \mathrm{CI}$ & $\mathbf{p}$ \\
\hline \multicolumn{2}{|c|}{ Age } & $63.27 \pm 6.980$ & $61.06 \pm 7.686$ & $0.16,4.26$ & $\mathbf{0 . 0 3 5}$ \\
\hline \multicolumn{2}{|c|}{ Weight } & $94.99 \pm 17.536$ & $93.67 \pm 19.580$ & $-3.86,6.51$ & 0.614 \\
\hline \multirow{2}{*}{ Gender } & Male & $48.0 \%(48)$ & $60.0 \%(60)$ & & \multirow[b]{2}{*}{0.089} \\
\hline & Female & $52.0 \%(52)$ & $40.0 \%(40)$ & & \\
\hline \multicolumn{2}{|c|}{ HTN } & $63.0 \%(63)$ & $51.0 \%(51)$ & & 0.087 \\
\hline \multicolumn{2}{|c|}{ Hepatic } & $11.0 \%(11)$ & $13.0 \%(13)$ & & 0.633 \\
\hline \multicolumn{2}{|c|}{ Renal } & $30.0 \%(30)$ & $45.0 \%(45)$ & & 0.028 \\
\hline \multicolumn{2}{|c|}{ RBS } & $123.60 \pm 23.259$ & $129.00 \pm 35.610$ & $-13.79,2.99$ & 0.206 \\
\hline
\end{tabular}

Table (7) showed Laboratory investigations and radiological workups done to the Linezolid and Vancomycin groups, and there was Infiltration in X-ray in 22 patients $(2 \%)$ unilaterally and in 78 patients $(78 \%)$ bilaterally in Linezolid group, while Infiltration in X-ray was unilateral in 31 patients $(31 \%)$ and bilateral in 69 patients $(69 \%)$ in Vancomycin group, this difference in infiltration in X-ray of the both groups did not show any statistically significance on the results of this study $(\mathrm{P}>0.05)$.

Pleural effusion was found in 48 patients (48\%) in Linezolid group and in 48 patients $(48 \%)$ in Vancomycin group, so there was no difference in finding Pleural effusion in both groups, therefore no statistically significance on the results of this study when comparing the both groups according to Pleural effusion $(\mathrm{P}>0.05)$.

Bacteremia was found in 9 patients (9\%) in Linezolid group and in 10 patients $(10 \%)$ in Vancomycin group, and this difference in finding Bacteremia in both groups did not show any statistically significance on the results of this study $(\mathrm{P}>0.05)$.

The organisms found in Linezolid group were MRSA in 64 patients $(64 \%)$, $\mathrm{G}$-ve in 22 patients (2\%) and $\mathrm{G}+\mathrm{ve}$ in 14 patients $(14 \%)$ while in Non-DM group there were MRSA in 56 patients $(56 \%), \mathrm{G}$ -ve in 26 patients $(26 \%)$ and $\mathrm{G}+\mathrm{ve}$ in 18 patients $(18 \%)$, and when comparing the effect of the both drugs on the different type of organisms. There was no statistically significance that effect of them in this study $(\mathrm{P}>0.05)$.

Table (7): Laboratory Investigations and radiological workup of Linezolid and Vancomycin groups:

\begin{tabular}{|c|c|c|c|c|}
\hline \multicolumn{2}{|c|}{$\begin{array}{ll}\text { Parameters } & \text { Groups } \\
\end{array}$} & $\begin{array}{l}\text { Linezolid group } \\
\quad(\mathbf{n}=\mathbf{1 0 0})\end{array}$ & $\begin{array}{l}\text { Vancomycin group } \\
(n=100)\end{array}$ & $\mathbf{p}$ \\
\hline \multirow{2}{*}{$\begin{array}{l}\text { Infiltration } \\
\text { in X-ray }\end{array}$} & Unilateral & $22.0 \%(22)$ & $31.0 \%(31)$ & \multirow{2}{*}{0.149} \\
\hline & Bilateral & $78.0 \%(78)$ & $69.0 \%(69)$ & \\
\hline \multicolumn{2}{|c|}{ Pleural effusion } & $48.0 \%(48)$ & $48.0 \%(48)$ & 1 \\
\hline \multirow{3}{*}{ Organism } & MRSA & $64.0 \%(64)$ & $56.0 \%(56)$ & \multirow{3}{*}{0.505} \\
\hline & G -ve & $22.0 \%(22)$ & $26.0 \%(26)$ & \\
\hline & G +ve & $14.0 \%(14)$ & $18.0 \%(18)$ & \\
\hline \multicolumn{2}{|c|}{ Bacteremia } & $9.0 \%(9)$ & $10.0 \%(10)$ & 0.809 \\
\hline
\end{tabular}


Table (8) showed the need for insulin and mechanical ventilation in the Linezolid and Vancomycin groups. There were 38 cases $(38 \%)$ who needed insulin in Linezolid group and 34 cases (34\%) needed insulin in Vancomycin group and this difference did not show any statistically significance $(\mathrm{P}<0.05) .46$ patients $(46 \%)$ needed Mechanical ventilation in Linezolid group, also 46 cases (46\%) in Vancomycin group needed Mechanical ventilation. There was no difference among the both groups for the need for Mechanical ventilation $(\mathrm{P}>0.05)$.

Table (8): Need for insulin and mechanical ventilation in Linezolid and Vancomycin groups

\begin{tabular}{|c|c|c|c|}
\hline Groups & $\begin{array}{c}\text { Linezolid group } \\
(\mathbf{n = 1 0 0})\end{array}$ & $\begin{array}{c}\text { Vancomycin group } \\
(\mathbf{n = 1 0 0})\end{array}$ & $\mathbf{p}$ \\
\hline Parameters & $38.0 \%(38)$ & $34.0 \%(34)$ & 0.556 \\
\hline $\begin{array}{c}\text { Mechananical } \\
\text { ventilation }\end{array}$ & $46.0 \%(46)$ & $46.0 \%(46)$ & 1 \\
\hline \multicolumn{2}{|r|}{ Data were expressed as percentage and frequency. } \\
\hline
\end{tabular}

Table (9) showed APACHE score and duration of hospital admission in the Linezolid and Vancomycin groups. The average APACHE score in Linezolid group was $12.03 \pm \mathrm{SD} 3.000$ and in Vancomycin group was $12.10 \pm$ SD 2.549 . This difference did not show any statistically significance in the results of this study $(\mathrm{P}>0.05)$. The average duration of hospital admission in Linezolid group was $18.18 \pm$ SD 3.099 and in Vancomycin group was $17.90 \pm \mathrm{SD}$ 2.966. This difference did not show any statistically significance in the results of this study $(\mathrm{P}>0.05)$.

Table (9): APACHE score and duration of hospital admission in Linezolid and Vancomycin groups

\begin{tabular}{|c|c|c|c|c|}
\hline Groups & $\begin{array}{c}\text { Linezolid group } \\
(\mathbf{n = 1 0 0})\end{array}$ & $\begin{array}{c}\text { Vancomycin group } \\
(\mathbf{n = 1 0 0})\end{array}$ & $\mathbf{9 5 \%} \mathbf{C I}$ & $\mathbf{p}$ \\
\hline Parameters & $12.03 \pm 3.000$ & $12.10 \pm 2.549$ & $-0.85,0.71$ & 0.859 \\
\hline APACHE & $18.18 \pm 3.099$ & $17.90 \pm 2.966$ & $-0.57,1.13$ & 0.515 \\
\hline Duration & \multicolumn{5}{|l}{} \\
\hline Data were expressed as mean and standard deviation. 95\% CI: 95\% confidence interval of \\
the mean difference between both groups.
\end{tabular}

Table (10) showed the treatment outcomes in Linezolid group versus Vancomycin group. The prevalence of poor (Complications) outcomes was $30.0 \%$ (30) and $37.0 \%$ (37) while the prevalence of good outcomes was $70.0 \%$ (70) and $63.0 \%$ (63) in Linezolid group versus Vancomycin group respectively with no statistically significant difference $(\mathrm{P}>0.05)$.

Table (10): Treatment outcome in Linezolid and Vancomycin groups:

\begin{tabular}{|c|c|c|c|}
\hline Treatment outcome & $\begin{array}{c}\text { Linezolid group } \\
(\mathbf{n = 1 0 0})\end{array}$ & $\begin{array}{c}\text { Vancomycin group } \\
(\mathbf{n = 1 0 0 )}\end{array}$ & $\mathbf{p}$ \\
\hline Poor (Complications) & $30.0 \%(30)$ & $37.0 \%(37)$ & \multirow{2}{*}{0.294} \\
\hline Good & $70.0 \%(70)$ & $63.0 \%(63)$ & \\
\hline \multicolumn{2}{|r|}{ Data were expressed as percentage and frequency. } \\
\hline
\end{tabular}


Table (11) showed the demographic characteristics and medical history of the studied subgroups in which the average age of DM \& Linezolid group was 63.06 years \pm SD 8.348 , the average age of DM $\&$ Vancomycin group was 62.40 years \pm SD 6.785 , the average age of NonDM \& Linezolid group was 63.48 years \pm SD 5.354 and the average age of NonDM \& Vancomycin group was 59.72 years \pm SD 8.345. These differences showed statistically significance among the results of this study, so age had effect when comparing the groups with each drug they were exposed to $(\mathrm{P}<0.05)$.

The average Weight of DM \& Linezolid group was $96.89 \mathrm{~kg} \pm$ SD 16.868, the average Weight of DM \& Vancomycin group was $89.31 \mathrm{~kg} \pm \mathrm{SD}$ 18.001 , the average Weight of Non-DM \& Linezolid group was $93.10 \mathrm{~kg} \pm \mathrm{SD}$ 18.152 and the average Weight of NonDM \& Vancomycin group was 98.03 $\mathrm{kg} \pm$ SD 20.292. These differences did not show any statistically significance among the results of this study $(\mathrm{P}>0.05)$.

DM \& Linezolid group had 27 males (54\%) and 23 females (46\%), DM \& Vancomycin group had 29 males (58\%) and 21 females (42\%), Non-DM \& Linezolid group had 21 males $(42 \%)$ and 29 females (58\%) and Non-DM \& Vancomycin had 31 males $(62 \%)$ and 19 females $(38 \%)$. These differences did not show any statistically significance among the results of this study $(\mathrm{P}>0.05)$.

DM \& Linezolid group had 34 patients (68\%) with HTN, DM \& Vancomycin group had 28 patients (56\%) with HTN, Non-DM \& Linezolid group had 29 patients (58\%) with HTN and Non-DM \& Vancomycin had 23 patients $(46 \%)$ with HTN with no statistically significance difference $(\mathrm{P}>0.05)$.

DM \& Linezolid group had 6 patients (12\%) with liver disease, DM \& Vancomycin group had 7 patients (14\%) with liver disease, Non-DM \& Linezolid group had 5 patients $(10 \%)$ with liver disease and Non-DM \& Vancomycin had 6 patients $(12 \%)$ with liver disease. These differences did not show any statistically significance among the results of this study $(\mathrm{P}>0.05)$.

DM \& Linezolid group had 23 patients (46\%) with renal disease, DM \& Vancomycin group had 30 patients $(60 \%)$ with renal disease, Non-DM \& Linezolid group had 7 patients (14\%) with renal disease and Non-DM \& Vancomycin had 15 patients (30\%) with renal disease. These differences showed statistically significance among the results of this study $(\mathrm{P}<0.05)$. So, the $\mathrm{DM}$ and drugs may increase the incidence of the renal disease among the patients.

The average RBS was $139.88 \mathrm{mg} / \mathrm{dl} \pm \mathrm{SD} 16.344$ in the $\mathrm{DM} \&$ Linezolid group, was $155.24 \mathrm{mg} / \mathrm{dl} \pm \mathrm{SD}$ 22.197 in DM \& Vancomycin group, was $107.32 \mathrm{mg} / \mathrm{dl} \pm \mathrm{SD} 16.882$ in Non-DM \& Linezolid group and was 102.76 $\mathrm{mg} / \mathrm{dl} \pm \mathrm{SD} 25.771$ in Non-DM \& Vancomycin group. These differences showed statistically significance among the results of this study $(\mathrm{P}<0.05)$. Therefore, the RBS was affected by the presence of DM and the drugs administrated. 
ISLAM EL-MORSY et al.,

Table (11): Demographic characteristics and medical history of the studied subgroups

\begin{tabular}{|c|c|c|c|c|c|c|}
\hline \multicolumn{2}{|c|}{ Parameters } & $\begin{array}{c}\text { DM \& } \\
\text { Linezolid }(n= \\
50)\end{array}$ & $\begin{array}{c}\text { DM \& } \\
\text { Vancomycin } \\
(\mathbf{n}=\mathbf{5 0})\end{array}$ & $\begin{array}{l}\text { Non-DM \& } \\
\text { Linezolid }(n= \\
50)\end{array}$ & $\begin{array}{c}\text { Non-DM \& } \\
\text { Vancomycin } \\
(\mathbf{n}=\mathbf{5 0})\end{array}$ & $\mathbf{p}$ \\
\hline \multicolumn{2}{|c|}{ Age } & $63.06 \pm 8.348$ & $62.40 \pm 6.785$ & $63.48 \pm 5.354$ & $59.72 \pm 8.345$ & 0.049 \\
\hline \multicolumn{2}{|c|}{ Weight } & $96.89 \pm 16.868$ & $89.31 \pm 18.001$ & $93.10 \pm 18.152$ & $98.03 \pm 20.292$ & 0.077 \\
\hline \multirow{2}{*}{ Gender } & Male & $54.0 \%(27)$ & $58.0 \%(29)$ & $42.0 \%(21)$ & $62.0 \%(31)$ & \multirow{2}{*}{0.212} \\
\hline & Female & $46.0 \%(23)$ & $42.0 \%(21)$ & $58.0 \%(29)$ & $38.0 \%(19)$ & \\
\hline \multicolumn{2}{|c|}{ HTN } & $68.0 \%(34)$ & $56.0 \%(28)$ & $58.0 \%(29)$ & $46.0 \%(23)$ & 0.173 \\
\hline \multicolumn{2}{|c|}{ Hepatic } & $12.0 \%(6)$ & $14.0 \%(7)$ & $10.0 \%(5)$ & $12.0 \%(6)$ & 0.945 \\
\hline \multicolumn{2}{|c|}{ Renal } & $46.0 \%(23)$ & $60.0 \%(30)$ & $14.0 \%(7)$ & $30.0 \%(15)$ & $<0.001$ \\
\hline \multicolumn{2}{|c|}{ RBS } & $\begin{array}{c}139.88 \pm \\
16.344\end{array}$ & $\begin{array}{c}155.24 \pm \\
22.197\end{array}$ & $\begin{array}{c}107.32 \pm \\
16.882\end{array}$ & $\begin{array}{c}102.76 \pm \\
25.771\end{array}$ & $<0.001$ \\
\hline
\end{tabular}

Table (12) showed laboratory Investigations and radiological workup of the studied subgroups, and in DM \& Linezolid group there were unilateral infiltration in X-ray in 10 cases $(20 \%)$ and bilateral in 40 cases $(80 \%)$, in DM \& Vancomycin group there were unilateral infiltration in X-ray in 17 cases (34\%) and bilateral in 33 cases $(66 \%)$, in Non-DM \& Linezolid group there were unilateral infiltration in X-ray in 12 cases $(24 \%)$ and bilateral in 38 cases $(76 \%)$ and in NonDM \& vancomycin group there were unilateral infiltration in X-ray in 14 cases $(28 \%)$ and bilateral in 36 cases $(72 \%)$. These differences did not show any statistically significance on the results of this study $(\mathrm{P}>0.05)$.

Pleural effusion was found in 27 cases (54\%) in DM \& Linezolid group, 25 cases $(50 \%)$ in DM \& vancomycin group, in 21 cases $(42 \%)$ in Non-DM \& Linezolid group and in 23 cases $(46 \%)$ in Non-DM $\&$ vancomycin group. These differences did not show any statistically significance on the results of this study $(\mathrm{P}>0.05)$.
Bacteremia was found in 4 cases $(8 \%)$ in DM \& Linezolid group, 6 cases $(12 \%)$ in DM \& vancomycin group, in 5 cases $(10 \%)$ in Non-DM \& Linezolid group and in 4 cases $(8 \%)$ in Non-DM \& vancomycin group. These differences did not show any statistically significance on the results of this study $(\mathrm{P}>0.05)$.

In DM \& Linezolid group, there were 34 patients $(68 \%)$ had MRSA, 9 patients (18\%) had G -ve organisms and 7 patients (14\%) had G +ve organisms, In DM \& Vancomycin group, there were 30 patients (60\%) had MRSA, 9 patients (18\%) had G -ve organisms and 11 patients (22\%) had $\mathrm{G}$ +ve organisms, In Non-DM \& Linezolid group, there were 30 patients $(60 \%)$ had MRSA, 13 patients $(26 \%)$ had $\mathrm{G}$-ve organisms and 7 patients (14\%) had $\mathrm{G}+\mathrm{ve}$ organisms and In Non-DM \& vancomycin group, there were 26 patients (52\%) had MRSA, 17 patients (34\%) had $\mathrm{G}$-ve organisms and 7 patients $(14 \%)$ had $\mathrm{G}+\mathrm{ve}$ organisms. These differences did not show any statistically significance on the results of this study $(\mathrm{P}>0.05)$. 
Table (12): Laboratory Investigations and radiological workup of the studied subgroups

\begin{tabular}{|c|c|c|c|c|c|c|}
\hline \multicolumn{2}{|c|}{ Groups } & $\begin{array}{c}\text { DM \& } \\
\text { Linezolid } \\
(n=50)\end{array}$ & $\begin{array}{c}\text { DM \& } \\
\text { Vancomycin } \\
(n=50)\end{array}$ & $\begin{array}{c}\text { Non-DM \& } \\
\text { Linezolid }(n= \\
50)\end{array}$ & $\begin{array}{c}\text { Non-DM \& } \\
\text { Vancomycin } \\
(n=50)\end{array}$ & $\mathbf{p}$ \\
\hline \multirow{2}{*}{$\begin{array}{c}\text { Infiltration } \\
\text { in X-ray }\end{array}$} & Unilateral & $20.0 \%(10$ & $34.0 \%(17$ & $24.0 \%(12$ & $28.0 \%(14$ & \multirow{2}{*}{0.432} \\
\hline & Bilateral & $80.0 \%(40$ & $66.0 \%(33$ & $76.0 \%(38$ & $72.0 \%(36$ & \\
\hline \multicolumn{2}{|c|}{ Pleural effusion } & $54.0 \%(27$ & $50.0 \%(25$ & $42.0 \%(21$ & $46.0 \%(23$ & 0.659 \\
\hline \multirow[b]{3}{*}{ Organism } & MRSA & $68.0 \%(34$ & $60.0 \%(30$ & $60.0 \%(30$ & $52.0 \%(26$ & \multirow{3}{*}{0.398} \\
\hline & G -ve & $18.0 \%(9$ & $18.0 \%(9$ & $26.0 \%(13$ & $34.0 \%(17$ & \\
\hline & G+ve & $14.0 \%(7$ & $22.0 \%(11$ & $14.0 \%(7$ & $14.0 \%(7$ & \\
\hline \multicolumn{2}{|c|}{ Bacteremia } & $8.0 \%(4$ & $12.0 \%(6$ & $10.0 \%(5$ & $8.0 \%(4$ & 0.887 \\
\hline \multicolumn{7}{|c|}{ Data were expressed as percentage and frequency. } \\
\hline
\end{tabular}

Table (13) showed the need for insulin and mechanical ventilation in the studied subgroups and in DM \& Linezolid group 38 patients $(76 \%)$ needed insulin, in DM \& Vancomycin group 34 patients $(68 \%)$ needed insulin and No cases need insulin in Non-DM with Linezolid group and in Non-DM with Vancomycin group. So, the insulin had a significant effect on the DM \& Linezolid and DM \& Vancomycin groups $(\mathrm{P}<0.05) .23$ patients $(46 \%)$ needed Mechanical ventilation in DM \& Linezolid group, 24 patients (48\%) needed Mechanical ventilation in DM \& Vancomycin group, 23 patients (46\%) needed Mechanical ventilation in NonDM \& Linezolid group, 22 patients (44\%) needed Mechanical ventilation in NonDM \& Vancomycin group, these differences did not show any statistically significance on the results of this study $(\mathrm{P}>0.05)$.

Table (13): Need for insulin and mechanical ventilation in the studied subgroups

\begin{tabular}{|c|c|c|c|c|c|}
\hline Groups & $\begin{array}{c}\text { DM \& } \\
\text { Linezolid } \\
(\mathbf{n = 5 0})\end{array}$ & $\begin{array}{c}\text { DM \& } \\
\text { Vancomycin } \\
(\mathbf{n = 5 0})\end{array}$ & $\begin{array}{c}\text { Non-DM } \\
\text { \&Linezolid } \\
(\mathbf{n = 5 0})\end{array}$ & $\begin{array}{c}\text { Non-DM \& } \\
\text { Vancomycin } \\
(\mathbf{n = 5 0})\end{array}$ & $\mathbf{p}$ \\
\hline Insulin & $\begin{array}{c}76.0 \% \\
(38\end{array}$ & $68.0 \%(34$ & $0.0 \%(0$ & $0.0 \%(0)$ & $<\mathbf{0 . 0 0 1}$ \\
\hline $\begin{array}{c}\text { Mechanical } \\
\text { ventilation }\end{array}$ & $\begin{array}{c}46.0 \% \\
(23\end{array}$ & $48.0 \%(24$ & $46.0 \%(23$ & $44.0 \%(22$ & 0.984 \\
\hline \multicolumn{7}{|c|}{ Data were expressed as percentage and frequency. } \\
\hline
\end{tabular}

Table (14) showed Bonferroni posthoc analysis of demographic characteristics and medical history of the studied subgroups according to the need of Insulin and Mechanical ventilation, when comparing the DM \& Linezolid group to DM \& Vancomycin group, there was no significant effect of the Insulin or Ventilation on those groups $(\mathrm{P}>0.05)$, when comparing the DM \& Linezolid group to Non-DM \& Linezolid group, there was a significant effect of the Insulin on DM \& Linezolid group $(\mathrm{P}<0.05)$ but
Mechanical ventilation had no significant effect on the both groups ( $\mathrm{P}>0.05)$.

When comparing, the DM \& Linezolid group to Non-DM \& Vancomycin group, there was a significant effect of the Insulin on $\mathrm{DM} \&$ Linezolid group $(\mathrm{P}<0.05)$ but Mechanical ventilation had no significant effect on the both groups $(\mathrm{P}>0.05)$.

When comparing the DM \& Vancomycin group to Non-DM \& Linezolid group, there was a significant effect of the Insulin on DM \& Vancomycin group $(\mathrm{P}<0.05)$ but 
Mechanical ventilation had no significant effect on the both groups ( $\mathrm{P}>0.05$ ), when comparing the DM \& Vancomycin group to Non-DM \& Vancomycin group, there was a significant effect of the Insulin on DM \& Vancomycin group $(\mathrm{P}<0.05)$ but
Mechanical ventilation had no significant effect on the both groups $(\mathrm{P}>0.05)$. The Insulin and Mechanical ventilation had no effect on the Non-DM \& Linezolid and Non-DM \& Vancomycin groups ( $\mathrm{P}>0.05)$.

Table (14): Bonferroni post-hoc analysis of demographic characteristics and medical history of the studied subgroups

\begin{tabular}{|c|c|c|c|}
\hline \multicolumn{4}{|c|}{ Groups Insulin Ventilation } \\
\hline DM \& Linezolid & DM \& Vancomycin & $>0.05$ & $>0.05$ \\
\hline DM \& Linezolid & Non-DM \& Linezolid & $<\mathbf{0 . 0 5}$ & $>0.05$ \\
\hline DM \& Linezolid & Non-DM \& Vancomycin & $<\mathbf{0 . 0 5}$ & $>0.05$ \\
\hline DM \& Vancomycin & Non-DM \& Linezolid & $<\mathbf{0 . 0 5}$ & $>0.05$ \\
\hline DM \& Vancomycin & Non-DM \& Vancomycin & $<\mathbf{0 . 0 5}$ & $>0.05$ \\
\hline Non-DM \& Linezolid & Non-DM \& Vancomycin & $>0.05$ & $>0.05$ \\
\hline
\end{tabular}

Table (15) showed APACHE score and duration of hospital admission in the studied subgroups and the average APACHE score was $19.34 \pm$ SD 3.001 in DM \& Linezolid group, was $18.92 \pm$ SD 2.747 in DM \& Vancomycin group, was $17.02 \pm$ SD 2.766 in Non-DM \& Linezolid group and was 16.88 $\pm \mathrm{SD}$ 2.847 in Non-DM \& Vancomycin group, these differences showed significant effect of the presence of DM and drugs on APACHE score $(\mathrm{P}<0.05)$.
The average duration of hospital admission was $12.56 \pm$ SD 3.098 in DM \& Linezolid group, was $12.48 \pm$ SD 2.628 in DM \& Vancomycin group, was $11.50 \pm$ SD 2.830 in Non-DM \& Linezolid group and was $11.72 \pm$ SD 2.433 in Non-DM \& Vancomycin group, these differences did not show significant effect of the presence of DM and drugs on the duration of hospital admission $(\mathrm{P}>0.05)$.

Table (15): APACHE score and duration of hospital admission in the studied subgroups

\begin{tabular}{|c|c|c|c|c|c|}
\hline Groups & $\begin{array}{c}\text { DM \& } \\
\text { Linezolid } \\
\text { Parameters }\end{array}$ & $\begin{array}{c}\text { DM \& } \\
\text { Vancomycin } \\
(\mathbf{n = 5 0})\end{array}$ & $\begin{array}{c}\text { Non-DM \& } \\
\text { Linezolid (n= } \\
\mathbf{5 0})\end{array}$ & $\begin{array}{c}\text { Non-DM \& } \\
\text { Vancomycin }(\mathbf{n}= \\
\mathbf{5 0})\end{array}$ & $\mathbf{p}$ \\
\hline APACHE & $\begin{array}{c}19.34 \pm \\
3.001\end{array}$ & $18.92 \pm 2.747$ & $17.02 \pm 2.766$ & $16.88 \pm 2.847$ & $<\mathbf{0 . 0 0 1}$ \\
\hline Duration & $\begin{array}{c}12.56 \pm \\
3.098\end{array}$ & $12.48 \pm 2.628$ & $11.50 \pm 2.830$ & $11.72 \pm 2.433$ & 0.135 \\
\hline \multicolumn{7}{|c|}{ Data were expressed as mean and standard deviation. 95\% CI: 95\% confidence interval of the mean } \\
difference between both groups
\end{tabular}

Table (16) showed Treatment outcome in the studied subgroups and there were 22 patients $(44 \%)$ who had Poor outcomes (Complications) and 28 patients $(56 \%)$ had Good outcomes in DM \& Linezolid group, there were 19 patients $(38 \%)$ who had Poor outcomes and 31 patients (62\%) had Good outcomes in DM \& Vancomycin group, there were 8 patients (22\%) who had Poor outcomes and 42 patients $(84 \%)$ had Good outcomes in Non-DM \& Linezolid group and there 
were 18 patients $(36 \%)$ who had Poor outcomes and 32 patients $(64 \%)$ had Good outcomes in Non-DM \& Vancomycin group, these differences showed statistically significance that the absence of DM had more good out comes than that with the presence of DM $(\mathrm{P}<0.05)$.

Table (16): Treatment outcome in the studied subgroups

\begin{tabular}{|c|c|c|c|c|c|}
\hline $\begin{array}{l}\text { Treatment } \\
\text { outcome }\end{array}$ & $\begin{array}{c}\text { DM \& } \\
\text { Linezolid } \\
(\mathbf{n}=50)\end{array}$ & $\begin{array}{c}\text { DM \& } \\
\text { Vancomycin } \\
(n=50)\end{array}$ & $\begin{array}{c}\text { Non-DM } \\
\text { \&Linezolid } \\
(\mathrm{n}=50)\end{array}$ & $\begin{array}{c}\text { Non-DM \& } \\
\text { Vancomycin } \\
(n=50)\end{array}$ & $\mathbf{p}$ \\
\hline $\begin{array}{c}\text { Poor } \\
\text { (Complications) }\end{array}$ & $44.0 \%(22)$ & $38.0 \%(19)$ & $16.0 \%(8)$ & $36.0 \%(18)$ & \multirow[t]{2}{*}{0.019} \\
\hline Good & $56.0 \%(28)$ & $62.0 \%(31)$ & $84.0 \%(42)$ & $64.0 \%(32)$ & \\
\hline
\end{tabular}

Table (17) showed Bonferroni posthoc analysis of demographic characteristics and medical history of the studied subgroups according to the outcomes, when comparing the DM \& Linezolid group to DM \& Vancomycin group, there was no significant effect on the outcomes after treatment $(\mathrm{P}>0.05)$, when comparing the DM \& Linezolid group to Non-DM \& Linezolid group, there was a significant effect of the DM on the outcomes $(\mathrm{P}<0.05)$.

When comparing the DM \& Linezolid group to Non-DM \& Vancomycin group, there was no significant effect of The DM on the outcomes after treatment $(\mathrm{P}>0.05)$, when comparing the DM \& Vancomycin group to Non-DM \& Linezolid group, there was no significant effect of the DM on the outcomes after treatment $(\mathrm{P}>0.05)$, when comparing the DM \& Vancomycin group to Non-DM \& Vancomycin group, there was no significant effect of the DM on the outcomes after treatment $(\mathrm{P}>0.05)$, Absence of DM had no effect on the outcomes on the Non-DM \& Linezolid and Non-DM \& Vancomycin groups $(\mathrm{P}>0.05)$.

Table (17): Bonferroni post-hoc analysis of demographic characteristics and medical history of the studied subgroups

\begin{tabular}{|c|c|c|}
\hline \multicolumn{3}{|c|}{ Groups Outcome } \\
\hline DM \& Linezolid & DM \& Vancomycin & $>\mathbf{0 . 0 5}$ \\
\hline DM \& Linezolid & Non-DM \& Linezolid & $<\mathbf{0 . 0 5}$ \\
\hline DM \& Linezolid & Non-DM \& Vancomycin & $>\mathbf{0 . 0 5}$ \\
\hline DM \& Vancomycin & Non-DM \& Linezolid & $>\mathbf{0 . 0 5}$ \\
\hline DM \& Vancomycin & Non-DM \& Vancomycin & $>\mathbf{0 . 0 5}$ \\
\hline Non-DM \& Linezolid & Non-DM \& Vancomycin & $>\mathbf{0 . 0 5}$ \\
\hline
\end{tabular}

\section{DISCUSSION}

Hospital-acquired pneumonia (HAP) is the most common health care- associated infection worldwide. HAP and ventilatorassociated pneumonia (VAP) remain important causes of morbidity despite improvements in prevention, antimicrobial therapy, and supportive care (Giuliano et al., 2018).

The optimal antibiotic therapy for the treatment of HAP caused by Grampositive organisms is controversial. However certain researches recommended that linezolid is superior to vancomycin in 
management of HAP (Wunderink et al., 2012). This has reawakened controversy regarding the optimal therapy for management of Gram-positive HAP (Kalil et al., 2013).

There are important public health reasons to resolve the controversy regarding the optimal treatment for Grampositive HAP. A perceived difference in clinical efficacy is likely to drive increased usage of one agent versus the other with consequent risk of unintended consequences (Kalil et al., 2013). In the case of linezolid, these include increased risk of outbreaks of linezolid resistant organisms, higher total drug costs and adverse drug events such as serotonin syndrome in patients with interacting medications and cytopenias in patients treated with prolonged courses (García et al., 2010). In the case of vancomycin, these include increased risk of clinical failure if the drug is underdosed, increased risk of nephrotoxicity if the drug is overdosed and central venous catheter complications such as bloodstream infections and thromboembolic disease (Kullar et al., 2011).

The current study aimed to assess the effect of treatment outcomes in patients with nosocomial pneumonia caused by methicillin-resistant staph aureus in diabetic patients and non-diabetic patients and comparison between linezolid and vancomycin clinical success rates in nosocomial pneumonia caused by methicillin-resistant staph aureus.

As regards demographic data, the current study revealed that there were no statistically differences among DM and Non diabetic groups. While, there were statistically significant differences among
Linezolid and Vancomycin groups as regards age only. In contrary, Equils et al. (2016) revealed that the demographic and baseline characteristics were similar between the linezolid and vancomycin treatment groups. Compared to the nondiabetic patients, the diabetic patients had a significantly higher percent: older than 50 years of age and heavier than $75 \mathrm{~kg}$.

As regards, medical history among DM and Non-DM groups, there were no statistically significant differences as regards HTN and hepatic affection while there were highly statistically significant differences in RBS and renal impairment. There were no statistically significant difference as regards HTN, hepatic affection and RBG while there was renal impairment in Vancomycin groups with statistically significant difference. Equils et al. (2016) revealed that he baseline nonfasting blood glucose levels were comparable among linezolid treated patients and vancomycin treated patients.

The current study revealed that there were poor outcomes as regards DM group in comparison to non-diabetic one with highly statistically significant results. In agreement, Korol et al. (2013) reported that patients with diabetes mellitus were at high risk for colonization and several types of infection with MRSA, especially pneumonia and soft tissue infections. This came in accordance with another researche which revealed that diabetic patients with complicated MRSA skin and soft tissue infections respond less well to treatment compared to non-diabetic ones (Lipsky et al., 2011). There were statistically significant differences among DM and Non-DM groups as the percentage of DM group developed poor 
outcomes (Complications) was $41 \%$ versus non-diabetic group (26\%) while the percentage of good outcomes in DM group was $59 \%$ versus $74 \%$ in non-DM groups.

As regards outcomes of the present study, there were statistically significant differences among DM and Non-DM groups as the percentage of DM group developed poor outcomes (Complications) was $41 \%$ versus non-diabetic group (26\%) while the percentage of good outcomes in DM group was $59 \%$ versus $74 \%$ in NonDM groups. There were no statistically significant differences among linezolid and vancomycin groups. The percentage of poor outcomes in Linezolid group was $30 \%$ versus $37 \%$ in vancomycin group, while the percentage of good outcomes in Linezolid group was $70 \%$ versus $67 \%$ in vancomycin group. In addition, among diabetic linezolid and vancomycin groups, rates of complications were comparable to some extent (44\% versus 38 respectively), while among Non-diabetic vancomycin groups revealed better outcomes than Linezolid group (36.0\% versus $16.0 \%$ ). In accordance, Equils et al. (2016) revealed that, among diabetic Linezolid and vancomycin groups, rates of study drugrelated adverse effects were similar. Moreover, Kalil et al. (2013) revealed in their study that, the clinical response analyses showed no differences between Linezolid and Vancomycin in the intention-to-treat as well as the per protocol patient populations. Moreover, the clinical response in the perprotocol patients with MRSA pneumonia likewise did not show differences between drugs. Therefore their secondary efficacy outcomes were also in agreement with their primary outcomes; both microbiological eradication and MRSA eradication were not different between vancomycin and linezolid.

Our efficacy findings were also in agreement with two previous metaanalyses performed by Kalil et al. (2010) and Walkey et al. (2011) that evaluated these antibiotics to treat HAP, and another meta-analyses performed by Beibei et al. (2010) evaluated these drugs and other antibiotics in patients with multiple sites of infection, including pneumonias. Consistency between the current study and prior meta-analysis despite being performed by different research groups using different statistical methods adds further confidence to our results. In contrary, Wunderink et al. (2012) revealed that linezolid has superior clinical efficacy compared to vancomycin.

The current study revealed that both groups were equal in the need of mechanical ventilation and the requirement of insulin revealed slight difference but not significant and patients treated with vancomycin had higher rates of mechanical ventilation.

The current study revealed that there were no statistically significant differences among the four study groups as regards the laboratory investigations microbial analysis (Gram positive, Gram negative and radiological workup). In addition, there were no statistically significant changes among APACHE score among linezolid and vancomycin groups while there were highly statistically significant differences among diabetic and non-diabetic groups which were reasonable owing to the associated co-morbidities that commonly presented in diabetic cases. In contrary, Wunderink 
et al. (2012) revealed that patients treated with vancomycin had more possibilities for bacteraemia, diabetes, renal failure and heart failure.

\section{CONCLUSION}

Diabetic comorbidity remains the main factor that affects the outcomes and prognosis of HAP cases. Higher complications and mortality rates were more in diabetic cases owing to their renal condition and uncontrolled diabetic status. Linezolid and vancomycin have similar efficacy and safety profiles in management of HAP cases.

\section{REFERENCES}

1. Beibei L, Yun $C$ and Mengli $C$ (2010): Linezolid versus vancomycin for the treatment of gram-positive bacterial infections: meta-analysis of randomised controlled trials. International journal of antimicrobial agents, 35(1): 3-12.

2. Di Yacovo, S., Garcia-Vidal, C., Viasus, D., Adamuz, J., Oriol, I., Gili, F., ... \& Carratala, J. (2013): Clinical features, etiology, and outcomes of communityacquired pneumonia in patients with diabetes mellitus. Medicine, 92(1):15.

3. Djahmi, N., Messad, N., Nedjai, S., Moussaoui, A., Mazouz, D., Richard, J. L., ... \& Lavigne, J. P. (2013): Molecular epidemiology of Staphylococcus aureus strains isolated from inpatients with infected diabetic foot ulcers in an Algerian University Hospital. Clinical Microbiology and Infection, 19(9): E398-E404.

4. Equils O, da Costa $C$ and Wible $M$ (2016): The effect of diabetes mellitus on outcomes of patients with nosocomial pneumonia caused by methicillin-resistant Staphylococcus aureus: data from a prospective double-blind clinical trial comparing treatment with linezolid versus vancomycin. BMC infectious diseases, 16(1): 476 (1-10).

5. García MS, De la Torre MÁ and Morales G (2010): Clinical outbreak of linezolid-resistant Staphylococcus aureus in an intensive care unit. JAMA, 303(22): 2260-2264.

6. Giuliano KK, Baker D and Quinn B (2018): The epidemiology of nonventilator hospital-acquired pneumonia in the United States. American journal of infection control, 46(3): 322-327.

7. Kalil AC, Klompas M and Haynatzki G (2013): Treatment of hospital- acquired pneumonia with linezolid or vancomycin: a systematic review and meta-analysis. BMJ open, 3(10): e003912.

\section{Kalil AC, Murthy MH and Hermsen ED} (2010): Linezolid versus vancomycin or teicoplanin for nosocomial pneumonia: a systematic review and meta-analysis. Critical care medicine, 38(9): 1802-1808.

9. Kalil, A. C., Metersky, M. L., Klompas, M., Muscedere, J., Sweeney, D. A., Palmer, L. B., ... \& El Solh, A. A. (2016): Management of adults with hospitalacquired and ventilator-associated pneumonia: 2016 clinical practice guidelines by the Infectious Diseases Society of America and the American Thoracic Society. Clinical Infectious Diseases, 63(5), e61-e111.

10.Korol E, Johnston $K$ and Waser $N$ (2013): A systematic review of risk factors associated with surgical site infections among surgical patients. PloS one, 8(12): e83743.

11.Kullar R, Davis SL and Levine DP (2011): Impact of vancomycin exposure on outcomes in patients with methicillinresistant Staphylococcus aureus bacteremia: support for consensus guidelines suggested targets. Clinical Infectious Diseases, 52(8): 975-981. 


\section{Lipsky BA, Itani KM and Weigelt JA} (2011): The role of diabetes mellitus in the treatment of skin and skin structure infections caused by methicillin-resistant Staphylococcus aureus: results from three randomized controlled trials. International Journal of Infectious Diseases, 15(2): e140-e146.

\section{Meyer E, Schwab $F$ and Gastmeier $P$} (2010): Nosocomial methicillin resistant Staphylococcus aureus pneumoniaepidemiology and trends based on data of a network of 586 German ICUs (20052009): European Journal of Medical Research, 15(12): 514.
14.Walkey AJ, O'Donnell MR and Wiener RS (2011): Linezolid vs glycopeptide antibiotics for the treatment of suspected methicillin- resistant Staphylococcus aureus nosocomial pneumonia: a metaanalysis of randomized controlled trials. Chest, 139(5): 1148-1155.

15.Wunderink RG, Niederman MS and Kollef MH (2012): Linezolid in methicillin-resistant Staphylococcus aureus nosocomial pneumonia: a randomized, controlled study. Clinical Infectious Diseases, 54(5): 621- 629. 


\section{مقارنة بين لينزوليد مقابل فانكومايسين في علاج مرضى

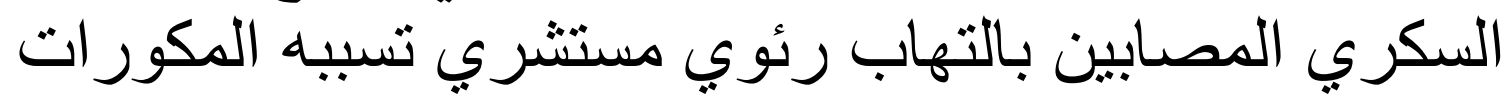

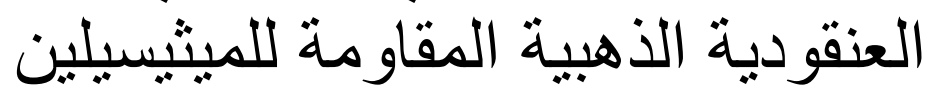

إسلام نمير محمد المرسي، أبو بكر هلال الأسمر، عبد الله سليمان أيوب الهيان قسم الأمراض الصدرية، كلية الطب، جامعة الأزهر

E-mail: islam.nomeir@ outlook.com

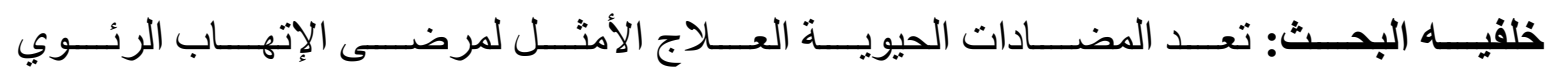

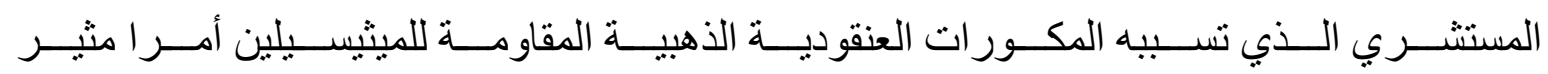

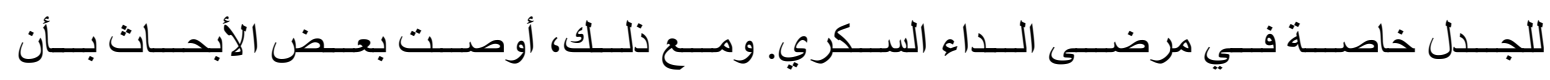

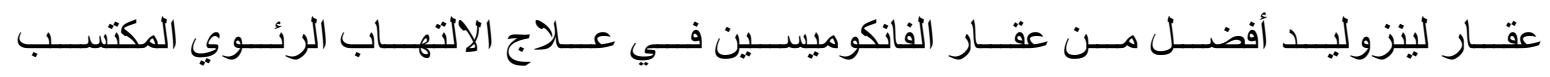

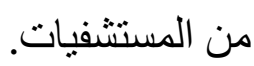

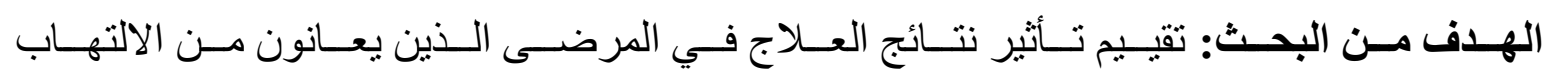

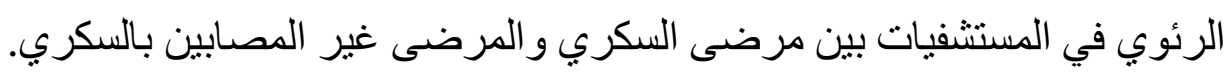

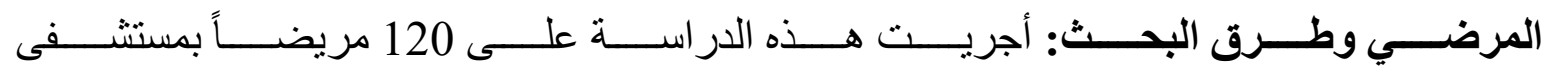

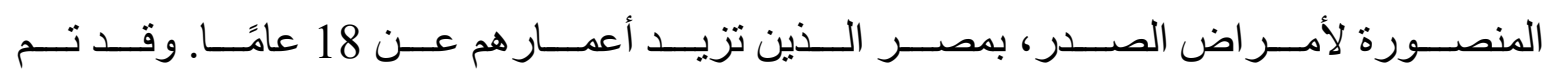

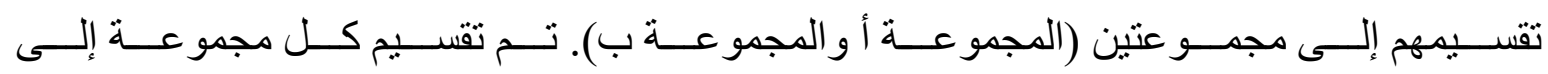

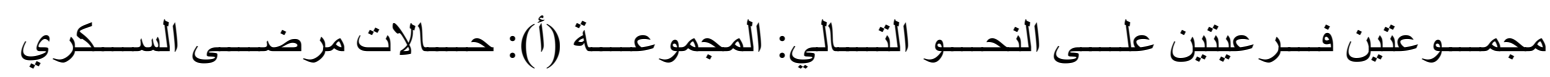

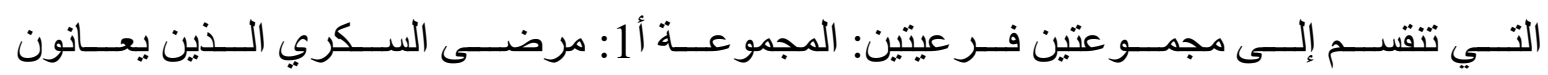

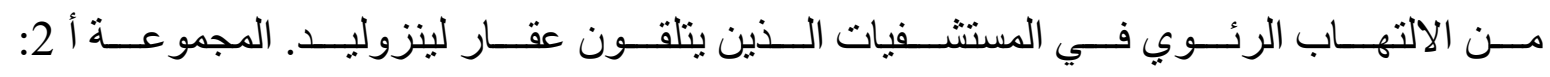

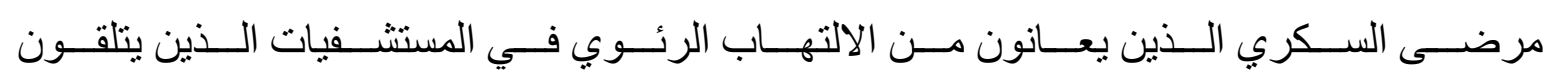

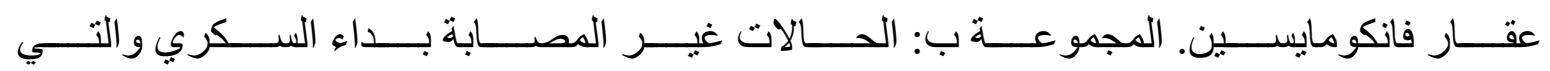

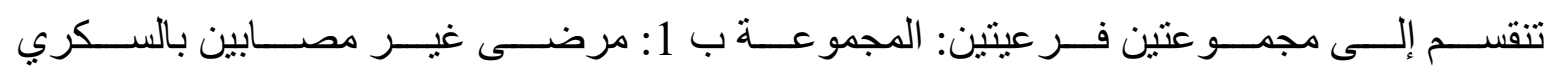

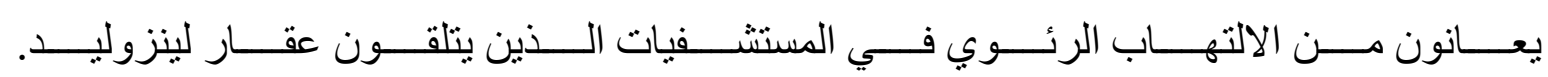

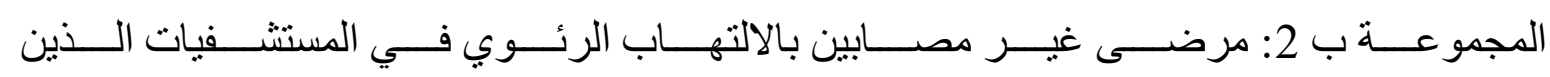

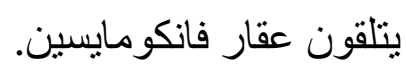




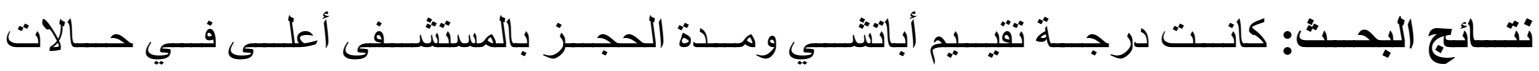

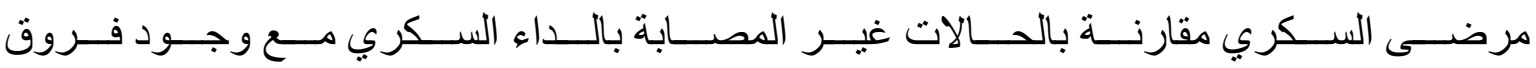

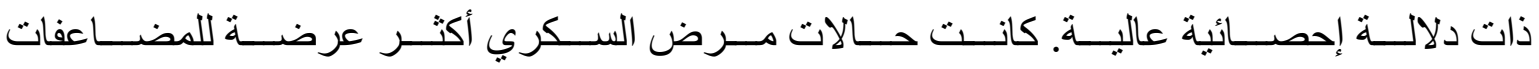

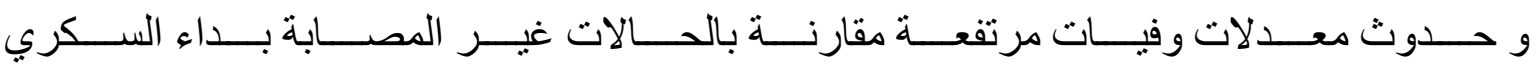

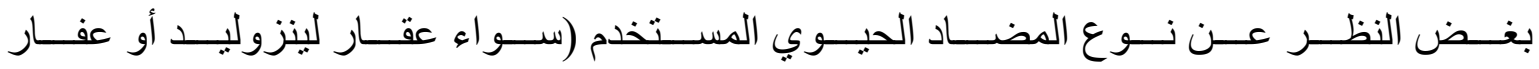

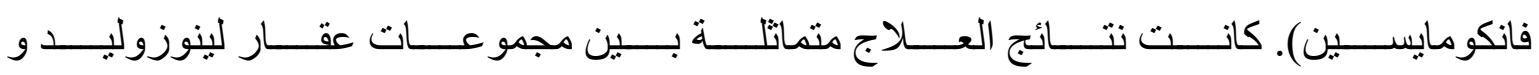
عقار فانكومايسن المستخدمة.

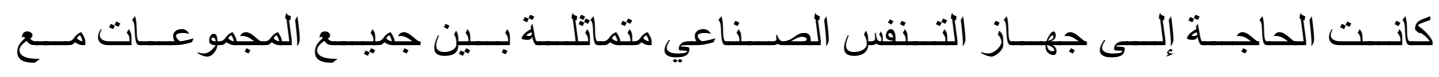
عدم وجود فرق ذو دلالة إحصائية.

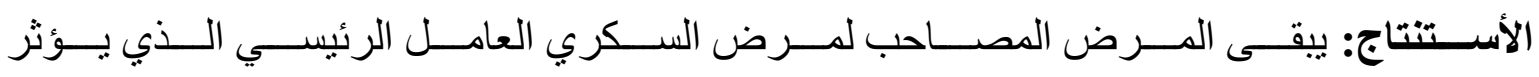

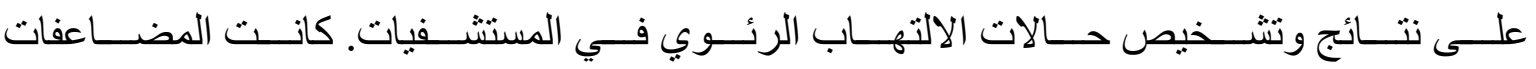

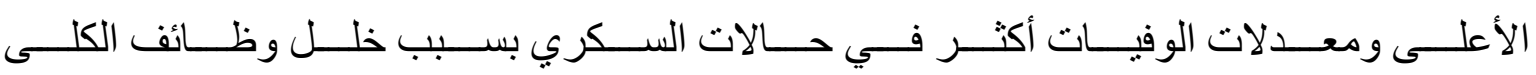

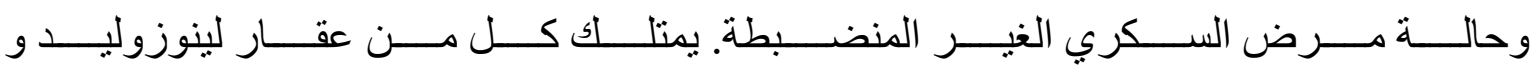

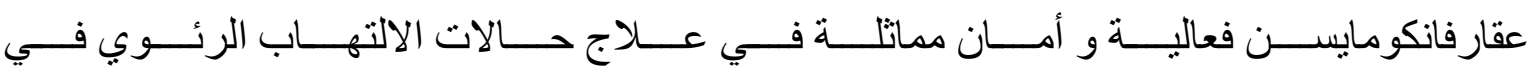
المستشفيات.

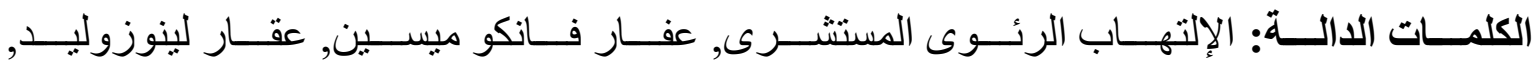
مرضى الداء السكرى. 